EGU21-13018, updated on 30 Jul 2021

https://doi.org/10.5194/egusphere-egu21-13018

EGU General Assembly 2021

(c) Author(s) 2021. This work is distributed under

the Creative Commons Attribution 4.0 License.

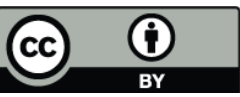

\title{
Extreme weather associated with atmospheric rivers over Morocco
}

Abdou Khouakhi, Fatima Driouech, Louise Slater, Toby Waine, Omar Chafki, and Otmane Raji Cranfield University, School of Water, Energy and Environment, Cranfield, United Kingdom of Great Britain - England, Scotland, Wales (a.khouakhi@cranfield.ac.uk)

Atmospheric rivers (ARs) are long, narrow, and transient corridors of enhanced water vapour content in the lower troposphere, often connected to the warm sector of extratropical cyclones and associated with strong low-level winds. These features play a major role in the global water cycle and drive weather extremes in many parts of the world. Here, we investigated the characteristics of landfilling ARs, including their frequency and magnitude over Morocco for the period 1979-2020. We used ECMWF ERA5 reanalysis data to detect and track landfilling ARs, and compared different gridded precipitation products (i.e. Integrated Multi-satellite Retrievals for GPM (IMERG), ERA5 Land, and CHIRPS) with a set of gauging stations datasets distributed across Morocco. We assessed AR association with rainfall at the annual and seasonal scales, as well as for extreme rainfall events, in different datasets. Preliminary results indicate that around 20 ARs/year make landfall or have their centroids within $200 \mathrm{~km}$ from Morocco. AR occurrence varies spatially and seasonally with highest occurrences in winter (DJF) across northern regions and spring (MAM) in the southern part of country. Rainfall events of up to $250 \mathrm{~mm} / \mathrm{year}$ are driven by ARs; with the southernmost and driest regions receiving most of their rainfall from ARs. This paper will provide an overview of extreme rainfall and wind associated with ARs across Morocco. 